\title{
Kanatlı çizel pullukta kullanılan kanatlarda farklı ağız yapılarının, ilerleme hızının ve iş derinliğinin çeki kuvveti üzerine etkisinin belirlenmesi
}

\section{Determination of effect of different wing mouth forms, different travelling speeds and different working depths on draft force in wings used in winged chisel plough}

\author{
Mustafa Gökalp BOYDAŞ \\ Atatürk Üniversitesi, Ziraat Fakültesi, Tarım Makinaları ve Teknolojileri Mühendisliği Bölümü, 25240 Erzurum \\ Sorumlu yazar (Corresponding author): M.G. Boydaş, e-posta (e-mail): mboydas@atauni.edu.tr
}

MAKALE BİLGİSİ

Alınış tarihi 02 Kassım 2016

Düzeltilme tarihi 02 Şubat 2017

Kabul tarihi 23 Ekim 2017

\section{Anahtar Kelimeler:}

Kanatlı çizel pulluk

Çeki kuvveti

Toprak ișleme

Toprak kanalı

\begin{abstract}
ÖZ
Toprak işleme aletlerinin analizinde ve tasarımında üzerinde durulan parametrelerden biri çek kuvvetinin azaltılmasıdır. Cizel gibi büyük çeki kuvveti gerektiren toprak ișleme aletlerinde bu daha önemlidir. Bu çalışma ile kanatlı çizelin kanat ağız yapısındaki değişik formların (K1, $\mathrm{K} 2$, K3 ve K4) özgül çeki kuvvetine olan etkileri incelenmiştir. K1 kanat yapısı düz bir ağza sahip olup geleneksel kullanılan kanat yapısına benzemektedir. K2, K3 ve K4 kanat ağızları ise farklı açılara sahip diş formundadır. Çalışmalar toprak kanalında yürütülmüştür. $\mathrm{Bu}$ kanatlar üç farklı ilerleme hızında $\left(0.12 \mathrm{~m} \mathrm{~s}^{-1}, 0.20 \mathrm{~m} \mathrm{~s}^{-1}\right.$ ve $\left.0.28 \mathrm{~m} \mathrm{~s}^{-1}\right)$ ve üç farklı is derinliğinde $(10 \mathrm{~cm}, 15 \mathrm{~cm}$ ve $20 \mathrm{~cm})$ denenmiştir. Kanat formunun özgül çeki kuvveti üzerine etkileri istatistiksel olarak önemli bulunmuştur. En yüksek özgül çeki kuvvetinin düz ağızl kanatta $(\mathrm{K} 1)$ meydana geldiği $\left(1.25 \mathrm{~N} \mathrm{~cm}^{-2}\right)$ ve en düşük özgül çeki kuvvetinin $\left(1.03 \mathrm{~N} \mathrm{~cm}^{-2}\right)$ dar açılı dişlere sahip kanatta (K4) meydana geldiği görülmüştür. İlerleme hızının ve iş derinliğinin artması özgül çeki kuvvetini önemli derecede artırmıştır.
\end{abstract}

\section{ARTICLE INFO}

Received 02 November 2016

Received in revised form 02 February 2017

Accepted 23 October 2017

\section{Keywords:}

Winged chisel

Draft

Soil tillage

Soil bin

\begin{abstract}
One of the parameters contemplated in analysis and design of soil tillage tools is the reduction of draft force. This is more important for soil tillage tools as chisel shank which needs large draft force. In this research, effect of various wing mouth forms (K1, K2, K3 ve K4) on specific draft of winged chisel was examined. K1 wing mouth form which has a smooth mouth is similar to the form used conventional wings. $\mathrm{K} 2, \mathrm{~K} 3$ and $\mathrm{K} 4$ wing mouth forms are the form of teeth with different angles. The study was conducted in soil bin. These wings were tested at three different travelling speeds $\left(0.12 \mathrm{~m} \mathrm{~s}^{-1}, 0.20 \mathrm{~m} \mathrm{~s}^{-1}\right.$ and $\left.0.28 \mathrm{~m} \mathrm{~s}^{-1}\right)$ and three different working depths $(10 \mathrm{~cm}, 15 \mathrm{~cm}$ and $20 \mathrm{~cm})$. Specific draft force was significantly affected from the wing forms. The highest specific draft force $\left(1.25 \mathrm{~N} \mathrm{~cm}^{-2}\right)$ obtained from the smooth mouth wing (K1), and the lowest specific draft force $\left(1.03 \mathrm{~N} \mathrm{~cm}^{-2}\right)$ occurred with the narrow angle teeth wing. An increase in travelling speed and working depth significantly increased the specific draft force.
\end{abstract}

\section{Giriş}

Toprak işlemede temel işlem toprağın kesilmesi, parçalanması ve gevşetilmesidir. Toprak işlemenin birçok amacı vardır. Bunlardan birkaçını sayacak olursak; iyi bir tohum yatağı hazırlamak, yabancı ot ve zararlı kontrolü yapmak, toprak ve su koruması sağlamak, kök gelişimini iyileştirmek, erozyon kontrolü ve su geçirgenliğini artırmak gibi önemli fonksiyonlar toprak işleme ile yerine getirilir. Günümüzde toprak işleme geleneksel ve koruyucu toprak işleme olarak iki ana kısma ayrılmaktadır (Koller 2003). Geleneksel toprak işleme kulaklı ve diskli pullukla yapılmakta olup temel görevi toprağı çevirerek altüst etmek, toprak yüzeyi üzerindeki yabancı ot tohum veya kalıntılarını, anızı, organik gübreyi gömmek, toprağı gevşetmektir (Vakali 2011). Ancak bu sistemin her toprak ve iklim şartına uygun olmadığı, rüzgâr ve su erozyonuna sebep olduğu ve toprak nem kaybını artırdığ 1 görülmüştür. Özellikle ülkemizde yaygın olarak kullanılan geleneksel toprak işleme ile toprak sıkışması ve erozyon büyük bir tehdit oluşturmaktadır. Ülkemiz topraklarının \% 34.4'ünün yüksek eğimli alanlardan (\% 15-40) oluşması bu durumu daha önemli kılmaktadır (Korucu ve ark. 1998). Geleneksel toprak işlemede görülen bu olumsuz yönler nedeniyle son yıllarda suyun ve toprağın korunması amaciyla koruyucu toprak işleme ön plana çıkmıştır. Koruyucu toprak işleme ile toprak yüzeyi üzerindeki bitki artıkları korunmakta, topraktaki nem kaybı 
minimuma indirilmekte ve erozyon önlenmektedir (Lal 1989; Subbulakshmi ve ark. 2009). Koruyucu toprak işleme kurak ve yarı kurak bölgeler için çok uygundur. Koruyucu toprak işlemede geleneksel toprak işlemeye oranla tarla geçiş sayısı daha azdır. $\mathrm{Bu}$ sistem ile bitki artıkları yüzeyde veya yüzeye yakın toprak katmanında bırakılır. Bu sistemin diğer bir önemli avantajı ise geleneksel toprak işlemede görülen isçilik, enerji tüketimi ve zamanlılık açısından daha tasarruflu olmasıdır. Koruyucu toprak işleme ile agregat stabilitesi ve organik madde içeriğinin yükseldiği böylece erozyon riskinin azaldığ 1 belirtilmiştir (Aykas ve ark. 2005). Koruyucu ve geleneksel toprak işlemenin karşılaştırıldığı çalışmalarda, koruyucu toprak işlemede toprak neminin \% 11 daha yüksek olduğu, su ile oluşan erozyonunun \% 52 ve toprak kaybının \% 80 azaldığ bildirilmiştir (Gao ve ark. 1999; Wang ve ark. 2000). Koruyucu toprak işlemede toprak devrilmeden işlenir. Bu nedenle yaygın olarak kullanılan toprak işleme aletlerinden biri çizeldir. Çizel de en önemli kısım ayak olup farklı boyut ve şekillerde imal edilmektedirler. Son y1llarda yaygınlaşmaya başlayan kanatlı çizel geleneksel çizel'e göre toprağa olumlu olan etkileri nedeniyle daha ön plana çıkmaya başlamıșdır (Kees 2008; Salar ve ark. 2013). Osman ve ark. (2014) klasik ve kanatl çizel ile yaptıkları bir çalışmada kanatlı çizelin darı verimini önemli ölçüde artırdığını belirtmiş̧lerdir. Kanatlı tip çizellerde ayağın her iki tarafina yatay veya belirli açıda kanatlar eklenmektedir (Şekil 1). Bu kanatlar yardımıyla toprak yatay olarak alttan kesilmektedir. Derin işlemeli çizel pullukların en önemli dezavantajlarından biri yüksek miktarda çeki kuvveti gereksinimleridir. Bu nedenle önemli bir enerji tüketimine yol açarlar. Meydana gelen bu yüksek çeki kuvveti toprak özelliklerine, toprak işleme aletinin hızına ve toprak işleme aletinin geometrik yapısına bağlı olarak değişir (Kushwaha ve ark. 1993; Boydaş 2004; Zadeh 2006; Armin 2014; Neisy ve ark. 2014). Çeki kuvveti bu gibi toprak işleme aletlerinin değerlendirilmesinde, imalat ve tasarım parametrelerinin geliştirilmesinde önemli bir göstergedir (Desbiolles ve ark. 1997; Saunders ve ark. 2000). Bu nedenle çeki kuvvetini azaltmaya yönelik araştırmaların yapılması önem arz eder.

Toprak işleme aletlerinde çeki kuvvetini belirlemek için yapılan teorik ve pratik çalışmalar incelendiğinde toprak özelliklerinin ve alet geometrisinin en önemli etken olduğu anlaşılmaktadır. Böylece alet geometrisinde yapılacak olan önemli değişiklikler, çeki kuvvetini önemli derecede etkileyecektir. İmalatı yapılan kanatlı çizellerin kanatlarının ağız kısımlarının genelde düz bir yapıda olduğu görülmektedir. Bu çalışma ile farklı ağız yapılarının çeki kuvveti üzerine olan etkisi incelenmiştir.

\section{Materyal ve Yöntem}

\section{1. Çizel kanatları}

Denemelerde kullanılan çizel kanatlar Tarım Makinaları ve Teknolojileri Mühendisliği Bölümü laboratuvarında St37 kalitesinde $4 \mathrm{~mm}$ kalınlığında çelik plakadan imal edilmiş̧tir. Kanatlara K1, K2, K3 ve K4 isimleri verilmiştir (Şekil 2). Bu kanatların boyutları Şekil 3'de sunulmuştur. Pratikte çizel kanatlar çizel ayağın her iki tarafina simetrik olarak bağlanmaktadır. Ancak bu çalışmada güçten tasarruf yapmak amacıyla tek taraflı kanat kullanılmıştır.

\section{2. Toprak Kanall}

Çalışma Atatürk Üniversitesi Ziraat Fakültesi Tarım Makinaları ve Teknolojileri Mühendisliği Bölümünde imal edilmiş olan $600 \mathrm{~cm}$ boyunda $80 \mathrm{~cm}$ genişliğinde ve $50 \mathrm{~cm}$ derinliğindeki toprak kanalında yürütülmüştür (Şekil 4). Toprak kanalı iki ana parçadan oluşmaktadır. 1: toprak kanalı üzerinde hareket eden araba 2: toprağın konulmuş olduğu ve arabanın hareket yolunu oluşturan kanal. Araba, toprak kanalı boyunca üzerinde bulunan redüktörlü bir trifaze $\mathrm{AC}$ elektrik motoru vasıtasıyla ileri geri hareket ederek çalışmaktadır. Arabanın hız kontrolü için ferekans invertörü kullanılmıştır. Böylece araba istenilen hızlarda çalıştırılabilmektedir.

\section{3. Çeki kuvveti ölçüm düzeneği}

Farklı ağız yapısına sahip çizel kanatlarından elde edilen çeki kuvveti değerlerini belirleyebilmek amaciyla bir adet $200 \mathrm{~kg}$ kapasiteye sahip ESİT marka lama tipi yük hücresi Şekil 5'de gösterildiği gibi arabaya monte edilmiştir.

Şekil 6'da gösterilen düzenek yardımıyla çeki kuvveti ölçümü yapılmıştır. Aşağıdaki eşitlik yardımıyla çeki kuvveti belirlenmiştir. Elde edilen çeki kuvveti değerlerinin aletin iş genişliği ve çalışma derinliğine bölünmesiyle özgül çeki kuvveti değeri bulunmuştur.

$$
F_{2}=\frac{F_{1} * L_{1}}{L_{2}}
$$

Burada, $\mathrm{F}_{1}$ : çizel kanadına gelen kuvvet $(\mathrm{N}), \mathrm{L}_{1}$ : kanat ile dönme ekseni arasındaki mesafe $(\mathrm{m}), \mathrm{L}_{2}$ : dönme ekseni ile yük hücresi ayar cıvatası arası mesafe (m).

Yük hücresi üzerine bağlanmış olan ayar cıvatası yardımıyla $(\alpha)$ boşluk açısı ayarı yapılmıştır. Denemelerde boşluk açısı $2^{\circ}$ olarak seçilmiştir. Yük hücresine etkiyen kuvvet elektriksel sinyale dönüştürülmüş daha sonra bir yükseltece ardından datalogger'a ve buradan da bilgisayara $0.01 \mathrm{~s}$ aralıklarla kaydedilmiştir (Şekil 7).

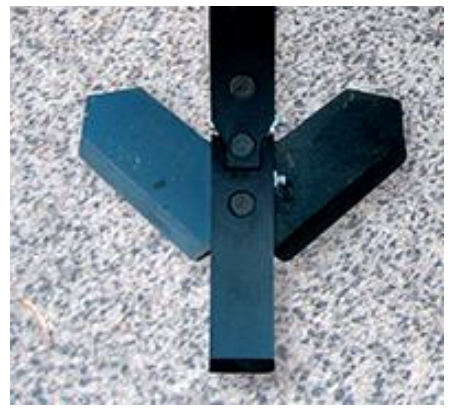

Şekil 1. Farklı yapılardaki kanatlı çizel pulluklar.

Figure 1. Different manufactured winged chisel plows.
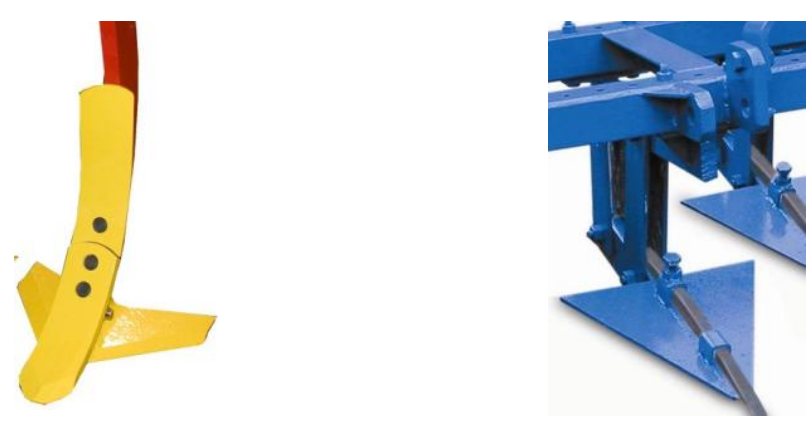


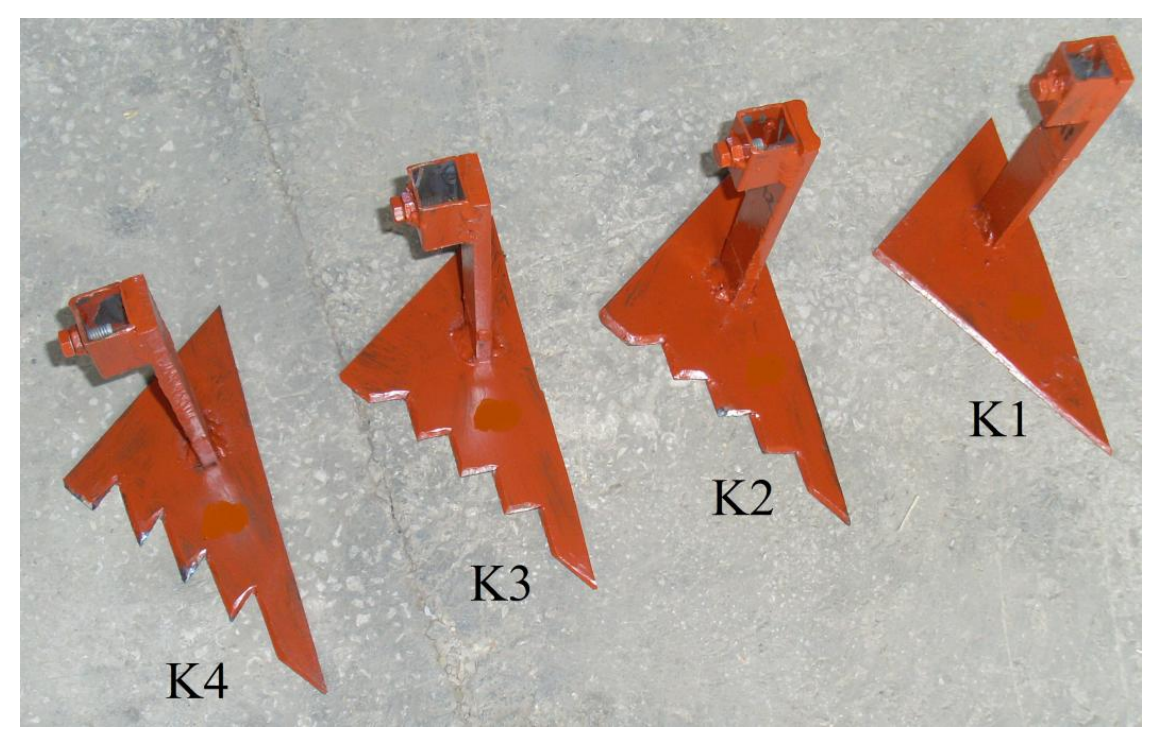

Şekil 2. Laboratuarda imal edilen farklı ağız yapısına sahip çizel pulluk kanatları.

Figure 2. Chisel plow wings with different mouth forms produced in the laboratory.
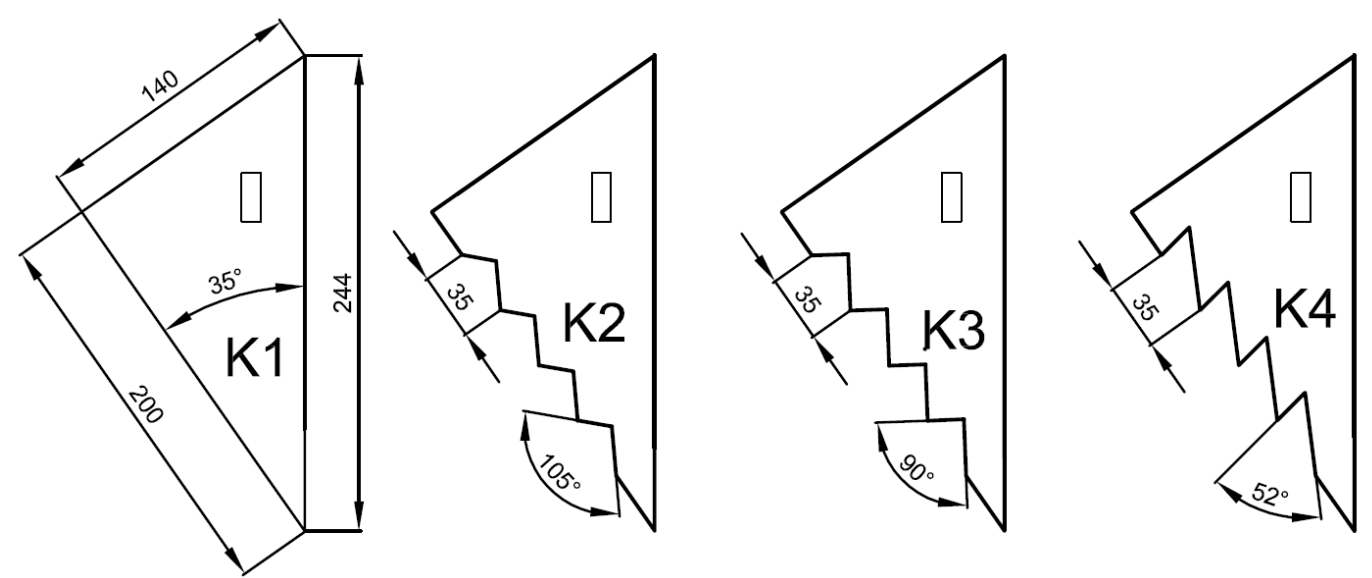

Şekil 3. Kanat ölçüleri.

Figure 3. Wing dimensions.

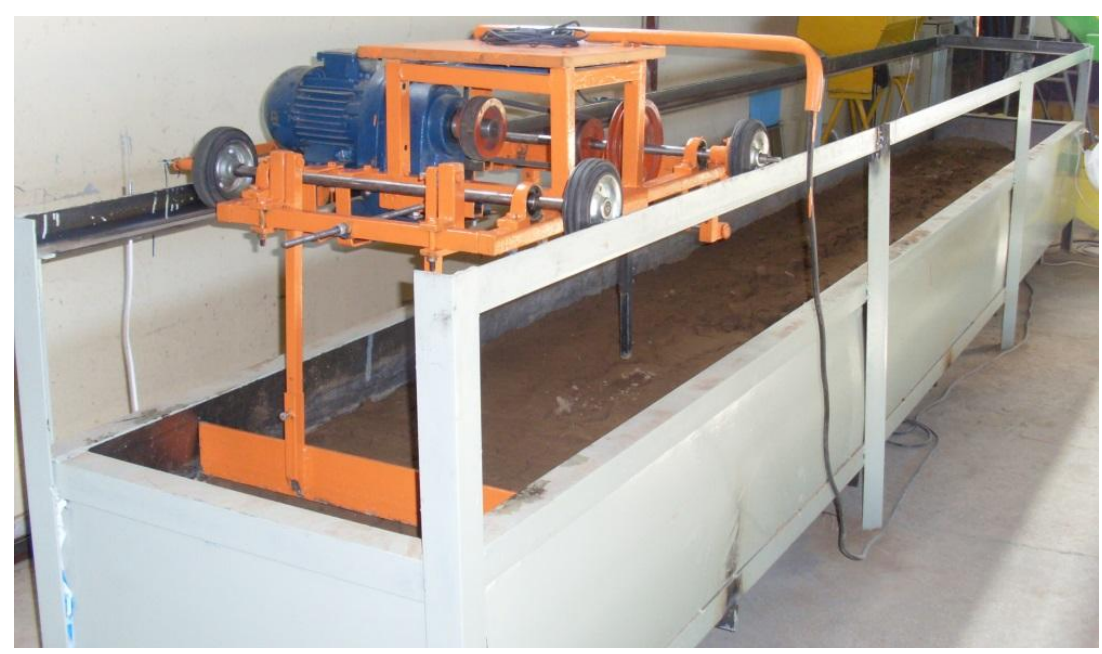

Şekil 4. Toprak kanalı.

Figure 4. Soil bin. 


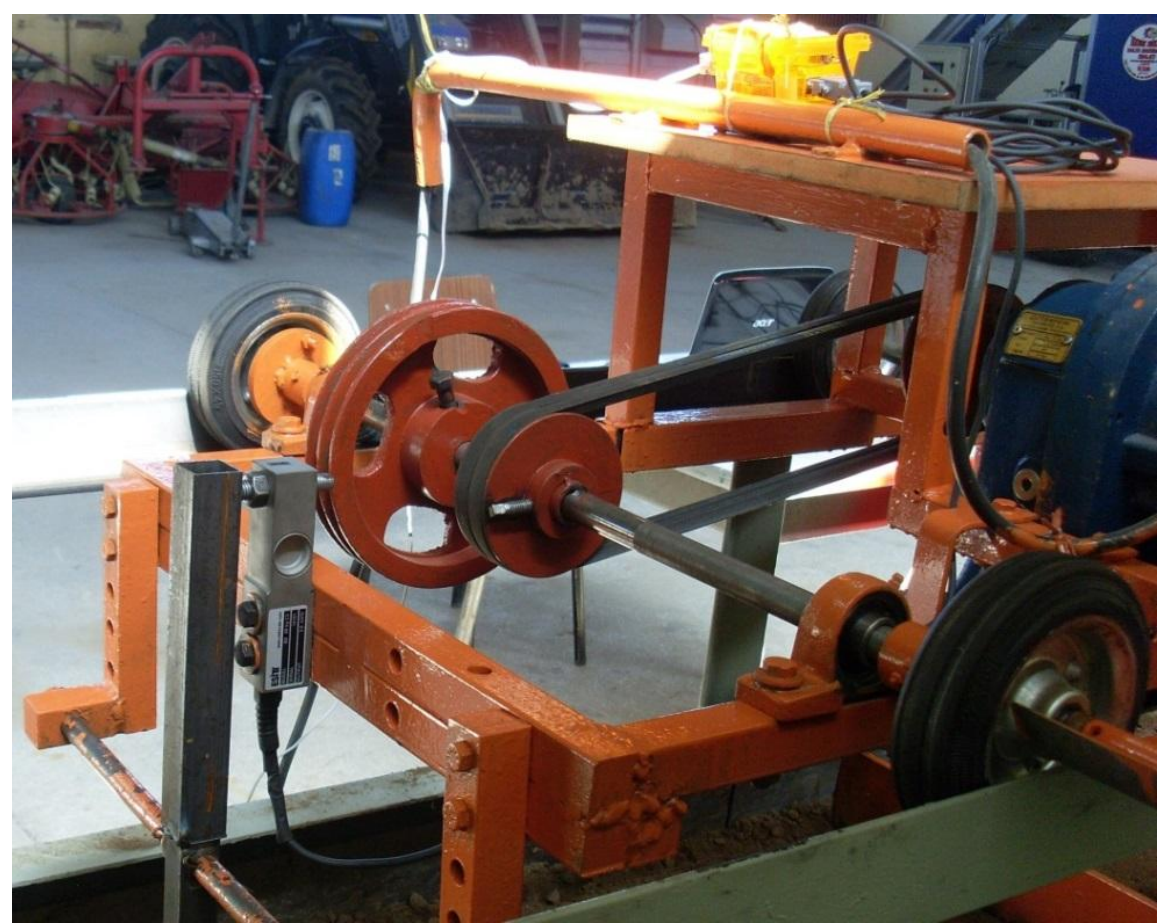

Şekil 5. Yük hücresinin bağlantısı.

Figure 5.Connection of the load cell.

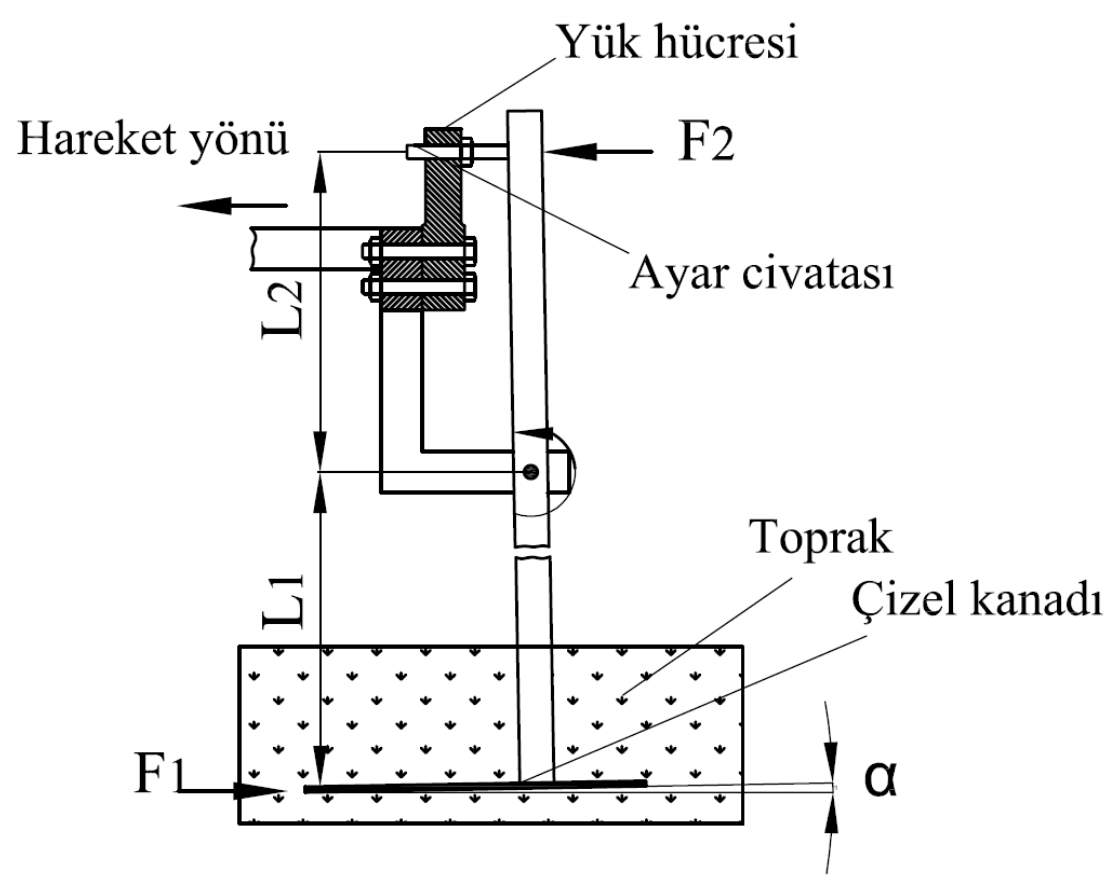

Şekil 6. Çeki kuvvetini belirlemede kullanılan düzenek.

Figure 6. The apparatus used to determine the draft force.

\subsection{Denemelerin yürütülmesi}

Denemelere başlanmadan önce toprak belirli nem seviyesine getirilmiş ve her denemeden önce TDR 300 nem ölçme aletiyle nem ölçümü yapılarak nem seviyesi kontrol edilmiş ve deneme boyunca sabit kalması sağlanmıştır. Yapılan her bir denemeden sonra toprak çapalanmış ve silindir yardımıyla sıkıştırılmıştır. Deneme boyunca toprak kanalında ölçülen ortalama toprak nem değerleri, penetrasyon direnci ve toprak hacim ağırlığı Çizelge 1'de verilmiştir.

Denemelerde $0.12,0.20$ ve $0.28 \mathrm{~m} \mathrm{~s}^{-1}$ ilerleme hizlar1 ve 10 , 15 ve $20 \mathrm{~cm}$ iş derinlikleri seçilmiştir. İstatistiksel analizler faktöriyel deneme planına göre 3 tekerrürlü olarak düzenlenmiştir. Verilerin istatistiksel olarak değerlendirilmesinde SPSS programı kullanılmıştır. Elde edilen veriler varyans analizine tabii tutulmuştur. 


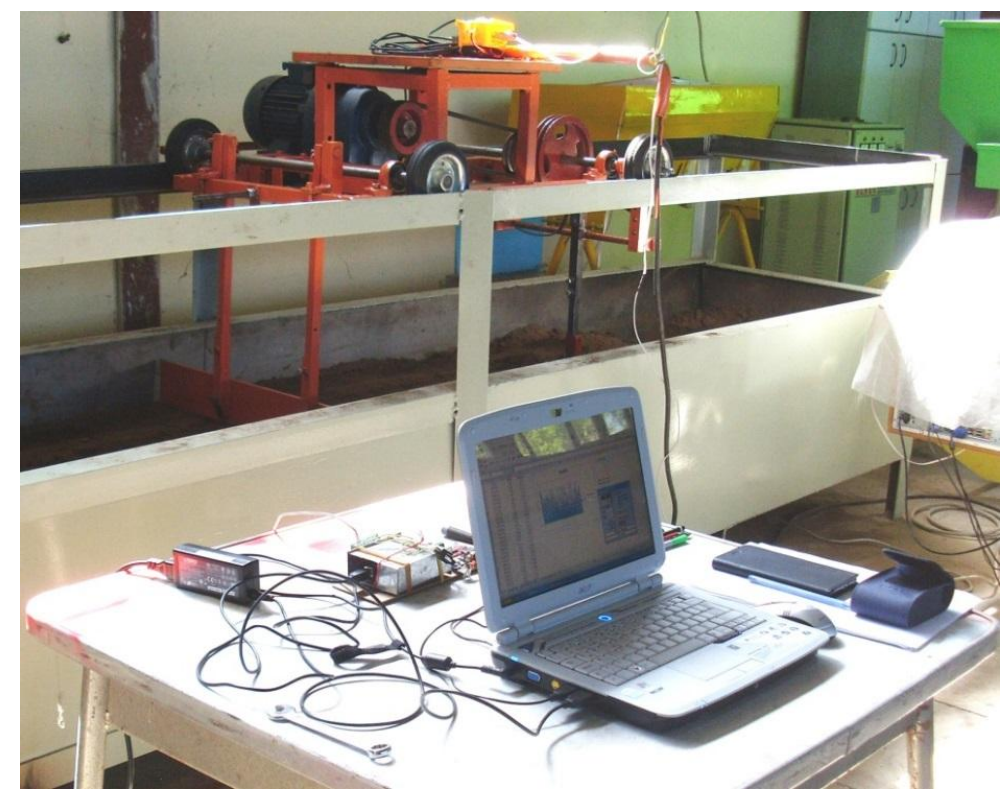

Şekil 7. Çeki kuvveti ölçüm düzeneği.

Figure 7. Draft force measurement system.

Çizelge 1. Toprak özellikleri.

Table 1. Soil properties.

\begin{tabular}{lccc}
\hline Toprak Özellikleri & $\mathbf{0 - 1 0} \mathbf{~ c m}$ & $\mathbf{1 0 - 1 5} \mathbf{~ c m}$ & \\
\hline Toprak hacim ağırlı̆̆ $\left(\mathrm{g} \mathrm{cm}^{-3}\right)$ & $1.38 \pm 0.08$ & $1.39 \pm 0.10$ & $\mathbf{1 5 - 2 0} \mathbf{~ c m}$ \\
Toprak penetrasyon direnci (Mpa) & $0.51 \pm 0.12$ & $0.52 \pm 0.15$ & $1.41 \pm 0.12$ \\
Toprak nemi (\%) & $15.18 \pm 1.23$ & $15.65 \pm 1.58$ & $0.54 \pm 0.09$ \\
\hline Kum (\%) & & 30 & $16.59 \pm 1.92$ \\
Silt (\%) & & 22 & \\
Kil (\%) & & Tin & \\
Bünye Sinıfi & & & \\
\hline
\end{tabular}

\section{Bulgular ve Tartışma}

Denemelerde kullanılan dört farklı çizel kanadın üç farklı iş derinliğinde ve üç farklı ilerleme hızında üç tekerrürlü olarak yapılan ölçümler sonucu belirlenen özgül çeki kuvveti varyans analizi sonuçları Çizelge 2'de sunulmuştur.

Varyans analizi sonuçlarına göre ilerleme hızının, iş derinliğinin ve kanat şeklinin istatistiksel olarak özgül çeki kuvvetini çok önemli düzeyde etkilediği görülmüştür $(\mathrm{P}<0.01)$. Kanat şekli, iş derinliği ve ilerleme hızı arasındaki interaksiyonların önemsiz çıktığı görülmüştür. Ortalama özgül çeki kuvveti değerleri ve Duncan Çoklu Karşılaştırma Testi sonuçları Çizelge 3'de ve denemeden elde edilen ortalama özgül çeki kuvveti sonuçlarına ait grafik Şekil 8'de sunulmuştur.

Çizelge 3 ve Şekil 8 incelendiğinde en yüksek özgül çeki kuvveti değerinin $1.26 \mathrm{~N} \mathrm{~cm}^{-2}$ ile düz ağızlı kanatta (K1) meydana geldiği görülmüştür. En düşük özgül çeki kuvveti ise $1.03 \mathrm{~N} \mathrm{~cm}^{-2}$ ile $\mathrm{K} 4$ kanadından elde edilmiştir. K3 ve K4 kanatlarından elde edilen ortalama özgül çeki kuvveti değerlerinin istatistiksel olarak aynı olduğu belirlenmiştir. Diş açısındaki küçülmenin özgül çeki kuvvetinde azalmaya neden olduğu belirlenmiştir. Li ve ark. (2015) peygamberdevesi kesici ve parçalayıcı kol yapısını dikkate alarak yaptıkları bir çalışmalarında bir adet düz ağız ve üç adet dişli ağız yapısına sahip bıçaklar ile toprağın kesme kuvvetini deneysel ve sonlu elemanlar yöntemini kullanarak analiz yapmışlardır. Düz ağız yapısına sahip bıçağın dişli bıçaklara oranla toprağı kesmek için daha fazla kuvvete ihtiyaç duyduğu belirtilmiştir.

İlerleme hızının artması ile tüm kanat yapılarında özgül çeki kuvveti değeri önemli derecede artmıştır. En yüksek ortalama özgül çeki kuvveti değeri $0.28 \mathrm{~m} \mathrm{~s}^{-1}$ ilerleme hızında 1.35 $\mathrm{N} \mathrm{cm}^{-2}$ olarak elde edilmiştir. En düşük değer ise $0.88 \mathrm{~N} \mathrm{~cm}^{-2}$ ile $0.12 \mathrm{~m} \mathrm{~s}^{-1}$ de elde edilmiştir. Benzer olarak iş derinliğinin artması ile ortalama özgül çeki kuvvetinde önemli düzeyde tüm kanat yapılarında artışı olduğu görülmüştür. En yüksek ortalama özgül çeki kuvveti değeri $20 \mathrm{~cm}$ iş derinliğinde 1.29 $\mathrm{N} \mathrm{cm}^{-2}$ olarak ölçülürken en düşük ortalama özgül çeki kuvveti değeri $10 \mathrm{~cm}$ iş derinliğinde $0.94 \mathrm{~N} \mathrm{~cm}^{-2}$ olarak bulunmuştur. Arvidsson ve ark. (2004), Van Muysen ve ark. (2000), AlSuhaibani ve Ghaly (2013) yapmış oldukları çalışmalarda iş derinliği ve ilerleme hızının çeki kuvveti üzerine önemli bir etkiye sahip olduğunu belirtmişlerdir. Payne (1956), Rowe ve Barnes (1961), Siemens ve ark. (1965), Gupta ve ark. (1989) ve Owen (1989) çeki kuvveti ve hız arasında doğrusal, polinom ve üstel bir ilişkinin olduğunu göstermişlerdir. Owen (1989), Raper (2005), Ndisya ve ark. (2016) tarafından çeki kuvvetinin işleme derinliğine bağlı olarak arttığı belirtilmiştir. Rahman ve Chan (2001) yaptıkları çalışmada çeki kuvveti üzerine çalışma derinliğinin ilerleme hızından daha etkin olduğunu ifade etmişlerdir. Ayrıca ASAE standartları D497.4 de basit çeki kuvveti tahmini değeri hesaplamak için geliştirilen eşitlikte çeki kuvvetinin ilerleme hızı, iş derinliği, iş genişliği, toprak tipi ve toprak işleme aletine bağlı olarak değiştiği ifade edilmiştir (ASAE 2003). 
Çizelge 2. Özgül çeki kuvveti varyans analizi sonuçları.

Table 2. Variance analysis results of specific draft force values.

\begin{tabular}{lcccc}
\hline Varyasyon Kaynakları & SD & \multicolumn{1}{c}{ KT } & KO & F \\
\hline Kanat şekli (K) & 3 & 0.76598 & 0.25533 & 31.78 \\
İlerleme hızı (H) & 2 & 4.1627 & 2.08135 & $0.000^{*}$ \\
İs derinliği (D) & 2 & 2.28601 & 1.14301 & $0.000^{*}$ \\
Tekerrür & 2 & 0.007 & 0.0035 & 142.29 \\
KxH & 6 & 0.04544 & 0.00757 & 0.44 \\
KxD & 6 & 0.00903 & 0.00151 & 0.94 \\
HxD & 4 & 0.0942 & 0.02355 & 0.19 \\
Hata & 82 & 0.65871 & 0.00803 & 0.469 \\
Toplam & 107 & 8.02907 & & 0.026 \\
\end{tabular}

*: $\mathrm{P}<0.01$ düzeyinde istatistiksel olarak çok önemli

SD: serbestlik derecesi

KT: kareler toplamı

KO: kareler ortalaması

Çizelge 3. Ortalama özgül çeki kuvveti değerleri ve Duncan Çoklu Karşılaştırma Testi sonuçları.

Table 3. Mean specific draft force values and Duncan Multiple Comparison Test results.

\begin{tabular}{|c|c|c|}
\hline \multicolumn{2}{|c|}{ Muamele } & \multirow{2}{*}{$\frac{\text { Özgül çeki kuvveti, } \mathrm{N} \mathrm{cm}^{-2}}{1.25 \mathrm{a}^{*}}$} \\
\hline \multirow{5}{*}{ Kanat şekli } & $\mathrm{K} 1$ & \\
\hline & $\mathrm{K} 2$ & $1.15 \mathrm{~b}$ \\
\hline & $\mathrm{K} 3$ & $1.08 \mathrm{c}$ \\
\hline & $\mathrm{K} 4$ & $1.03 \mathrm{c}$ \\
\hline & LSD & 0.064 \\
\hline \multirow{4}{*}{ İlerleme hızı, $\mathrm{m} \mathrm{s}^{-1}$} & 0.12 & $0.88 \mathrm{c}$ \\
\hline & 0.20 & $1.16 \mathrm{~b}$ \\
\hline & 0.28 & $1.35 \mathrm{a}$ \\
\hline & LSD & 0.56 \\
\hline \multirow{4}{*}{ İş derinliği, cm } & 10 & $0.94 \mathrm{c}$ \\
\hline & 15 & $1.15 \mathrm{~b}$ \\
\hline & 20 & $1.29 \mathrm{a}$ \\
\hline & LSD & 0.56 \\
\hline
\end{tabular}

*Aynı harfi taşıyan ortalamalar arasındaki farklar istatistiksel olarak önemli değildir $(\mathrm{P}<0.01)$.

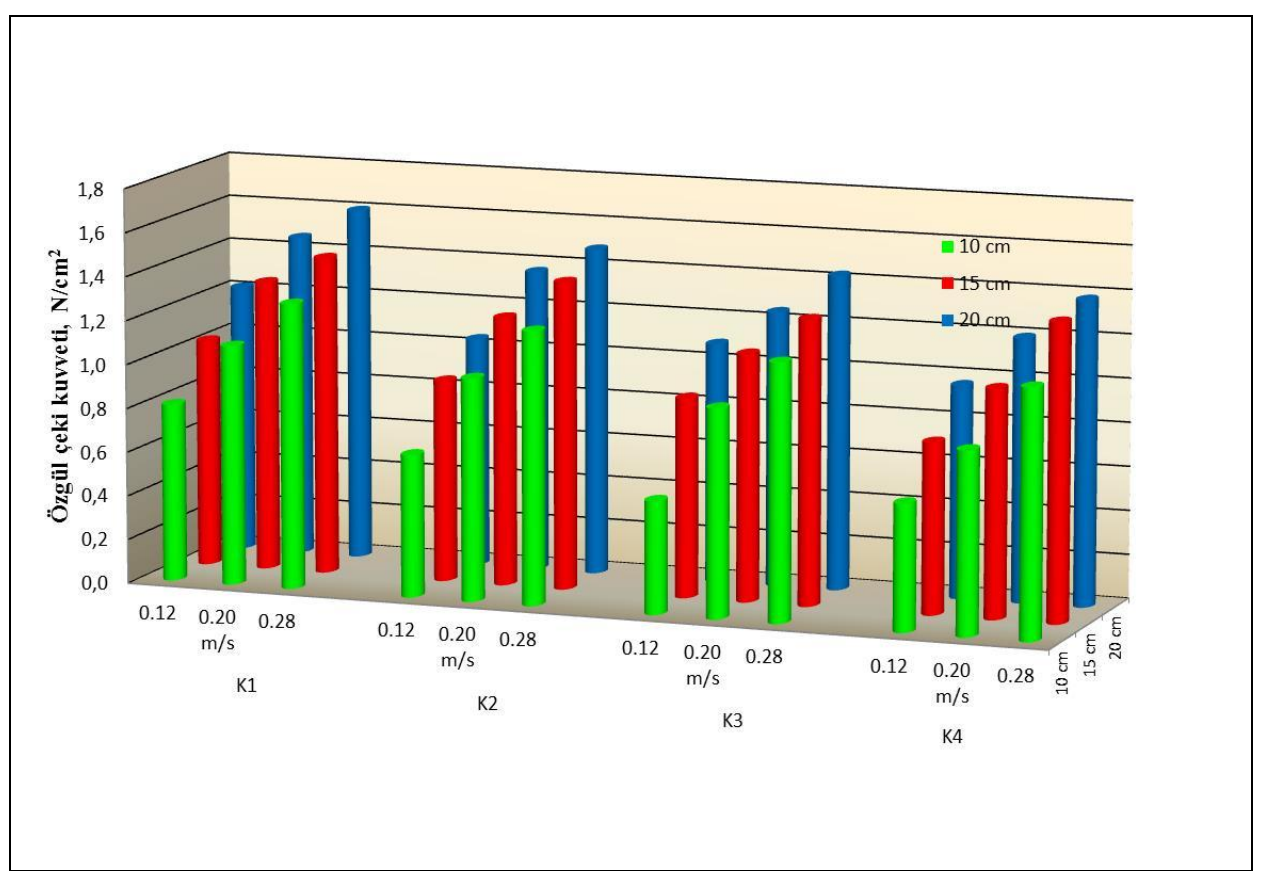

Şekil 8. Farklı çizel kanatlarından elde edilen ortalama özgül çeki kuvveti değerlerinin ilerleme hızına ve iş derinliğine bağlı olarak değişimi.

Figure 8. Change of specific draft force values obtained from different chisel plow wings depend on travelling speed and working depth. 


\section{Sonuç}

Laboratuar şartlarında toprak kanalında yapılan bu çalışma ile kanatlı çizel ayakta kullanılan kanatlarda farklı ağız yapısının özgül çeki kuvvetine olan etkisi incelenmiştir. Denemede farklı hız ve farklı iş derinliklerinin özgül çeki kuvvetine etkisi de belirlenmiştir. Kanat ağız yapısının özgül çeki kuvveti üzerine önemli bir etkiye sahip olduğu görülmüştür. Testere formundaki bir ağız yapısının düz ağız yapısına sahip bir kanada göre özgül çeki kuvvetini önemli derecede azalttığı belirlenmiştir. Özellikle testere diş açısının azalmasıyla özgül çeki kuvvetinin azaldığı, testere diş açısının artmasıyla özgül çeki kuvvetinin arttığı belirlenmiştir. İlerleme yönüne $90^{\circ}$ açı yapan çizel kanattan elde edilen özgül çeki kuvveti değeri $\left(1.08 \mathrm{~N} \mathrm{~cm}^{-2}\right)$ ile $52^{\circ}$ açı yapan çizel kanattan elde edilen özgül çeki kuvveti değerinin $\left(1.03 \mathrm{~N} \mathrm{~cm}^{-2}\right)$ istatistiksel olarak aynı olduğu görülmüştür. Dar açılı testere dişli kanatlarda görülebilecek mahsurlar (örneğin taş sıkışması gibi) dikkate alındığında elde edilen bu sonuç daha önem taşımaktadır. Ayrıca dar açılı testere dişli kanatların toprak altındaki bitki köklerini daha iyi keseceği önemli bir avantajdır. Tarla şartlarında yapılacak sonraki çalışmalarla bu gibi avantaj ve dezavantajlar daha net tespit edilmeye çalışılacaktır. Önceki araştırmalarda da görüldüğü gibi İlerleme hızındaki ve iş derinliğindeki artışın tüm kanat formlarında özgül çeki kuvvetini artırdığı görülmüştür.

\section{Teşekkür}

$\mathrm{Bu}$ projeye katkı sağlayan Atatürk Üniversitesi Bilimsel Araştırma Projeleri Komisyonuna teşekkür ederim.

\section{Kaynaklar}

Al-Suhaibani SA, Ghaly AE (2013) Comparative study of the kinetic parameters of three chisel plows operating at different depths and forward speed in a sandy soil. The International Journal of Engineering and Science 2: 42-59.

Armin A (2014) Mechanics of soil-blade interaction. PhD Thesis, Department of Mechanical Engineering University of Saskatchewan, Saskatoon.

Arvidsson J, Keller T, Gustafsson K (2004) Specific draught for moldboard plough, chisel plough and disc harrow at different water contents. Soil and Tillage Research 79: 221-231.

ASAE (2003) ASAE Standard D497.4: Agricultural Machinery Management Data. ASAE, St. Joseph, Michigan, USA.

Aykas E, Yalçın H, Çakır E (2005) Koruyucu toprak işleme yöntemleri ve doğrudan ekim. Ege Üniversitesi Ziraat Fakültesi Dergisi 42(3): 195-205.

Boydaş MG (2004) Buğday tarımında kullanılan bazı birincil toprak işleme aletlerinde değişik yapısal özelliklerin toprağın fiziksel özelliklerine, iş başarısına, çeki gücü ve yakıt tüketimine etkileri. Doktora tezi, Atatürk Üniversitesi Fen Bilimleri Enstitüsü Tarım Makinaları ABD.

Desbiolles JMA, Godwin RJ, Kilgour J, Blackmore BS (1997) A novel approach to the prediction of tillage tool draught using a standard tine. J. Agric. Engng Res. 66: 295-309.

Gao HW, Li HW, Chen JD (1999) Research on sustainable mechanized dryland farming. Agric. Res. Arid Areas 1: 57-62.

Gupta PD, Gupta CP, Pandey KP (1989) An analytical model for predicting draft forces on convex type cutting blades. Soil and Tillage Research 14: 131-44.

Kees G (2008) Using subsoiling to reduce soil compaction. USDA Forest Service Technology and Development Program Missoula, MT. d/pubs/pdfpubs/pdf08342828/pdf08342828dpi72.pdf. Erişim 15 Mayis 2016.

Koller I (2003) Techniques of soil tillage 1-25 p. In: Adel El Titi (Ed.). Soil tillage in agroecosystems, CRC Press, Boca Raton.

Korucu T, Kirişçi V, Görücü S (1998) Korumalı toprak işleme ve Türkiye'deki uygulamaları. 18. Ulusal Tarımsal Mekanizasyon Kongresi Bildiriler Kitab1, 321-333, Tekirdağ.

Kushwaha RL, Chi L, Shen J (1993) Analytical and numerical models for predicting soil forces on narrow tillage tools- A Review. Canadian Agricultural Engineering 35(3): 183-193.

Lal R (1989) Conservation tillage for sustainable agriculture: tropics vs. temperate environments. Advances in Agronomy 42: 8-197.

Li M, Yang Y, Guo L, Chen D, Sun H, Tong J (2015) Design and analysis of bionic cutting blades using finite element method. Applied Bionics and Biomechanics 2: 1-7.

Ndisya J, Gitau A, Mbuge D, Hiuhu A (2016) The effect of the operational parameters on the draft requirement of ripping in a sandy clay soil. Open Journal of Optimization 5: 1-13.

Neisy A, Jamshidi AR, Tayari E, Attaie P (2014) Introduction to the energy requirements by a tillage tool. WALIA Journal 30(1): 35-38.

Osman TO, Zaied MB, El Naim AM (2014) Field performance of a modified chisel plow. International Journal of Natural Sciences Research 2(6): 85-96.

Owen GT (1989) Subsoiling forces and tool speed in compact soils. Canadian Agricultural Engineering 31(1): 15-20.

Payne PC (1956) The relationship between the mechanical properties of soil and the performance of simple cultivation implements. J. Agric. Engng Res. 1: 23-50.

Rahman S, Chen Y (2001) Laboratory investigation of cutting forces and soil disturbance resulting from different manure incorporation tools in a loam sand soil. Soil and Tillage Research 58(1): 19-29.

Raper RL (2005) Subsoiler shapes for site-specific tillage. Applied Engineering in Agriculture 21(1): 25-30.

Rowe RJ, Barnes KK (1961) Influence of speed on elements of draft of a tillage tool. Transaction of ASAE 4(1): 55-57.

Salar MR, Esehaghbeygi A, Hemmat A (2013) Soil loosening characteristics of a dual bent blade subsurface tillage implement. Soil and Tillage Research 134: 17-24.

Saunders CR, Godwin J, O’Dogherty MJ (2000) Prediction of soil forces acting on mouldboard ploughs. Fourth International Conference on Soil Dynamics, Adelaide, Australia, March, 26-30.

Siemens JC, Weber JA, Thornburn TH (1965) Mechanics of soil as influenced by model tillage tools. Transaction of ASAE 8(1): 1-7.

Subbulakshmi S, Harisudan C, Saravanan C, Subbian P (2009) Conservation tillage an eco friendly management practices for agriculture. Research Journal of Agriculture and Biological Sciences 5(6): 1098-1103.

Vakali C, Zaller JG, Kopke U (2011) Reduced tillage effects on soil properties and growth of cereals and associated weeds under organic farming. Soil and Tillage Research 111: 133- 141.

Wang XY, Gao HW, Li HW, Zhou XX (2000) Experimental study on runoff and erosion under conservation tillage. Transaction of ASAE 3: 66-69.

Van Muysen W, Govers G, Van Oost K, Van Rompaey A (2000) The effect of tillage depth, tillage speed and soil condition on chisel tillage erosivity. Journal of Soil and Water Conservation 55(3): 355-364.

Zadeh SRA (2006) Modelling of energy requirements by A narrow tillage tool. $\mathrm{PhD}$ Thesis, Department of Agricultural and Bioresource Engineering University of Saskatchewan, Saskatoon. 